\title{
ARQUITETURA VERDE: CONTRIBUIÇÕES A PARTIR DA EXEMPLIFICAÇÃO DE TIPOLOGIAS VINCULADAS À SUSTENTABILIDADE URBANA
}

\author{
Maria Eliza Alves Guerra ${ }^{1}$
}

Anaísa Filmiano Andrade Lopes ${ }^{2}$

\begin{abstract}
RESUMO
O descompasso entre os investimentos públicos em infraestrutura, o rápido processo de urbanização, e a ausência de um planejamento capaz de suprir as necessidades da população, provocou graves danos no sistema urbano das cidades, tais como construções insustentáveis, congestionamentos, geração de resíduos, escassez de recursos naturais, dentre outros. Devido ao conjunto desses fatores, associar a arquitetura verde à gestão do meio urbano é fundamental para o desenvolvimento da cidade sustentável. A arquitetura verde é aquela que projeta reconhecendo que a cidade precisa atender aos objetivos sociais e ambientais, assim os arquitetos como projetistas possuem um importante papel a ser desempenhado. A presente pesquisa tem como objetivo abordar sobre os assuntos relacionados à sustentabilidade urbana, exemplificando as tipologias ou padrõesde algumas cidades que são capazes de assegurar uma boa relação com o meio. O procedimento metodológico foi pautado em análise bibliográfica, para tanto, foi explanado definições sobre o tema, destacando os recursos tipológicos para a implementação da sustentabilidade no ambiente urbano. Os resultados são promissores e destacam casos urbanos que estão resolvendo seus problemas de forma eficiente através de princípios sustentáveis.
\end{abstract}

PALAVRAS-CHAVE: Arquitetura Verde. Cidades Sustentáveis. Recursos Tipológicos. Ambiente Urbano

\footnotetext{
${ }^{1}$ Prof $^{\mathrm{a}} \mathrm{Dr}^{\mathrm{a}}$ da Faculdade de Arquitetura e Urbanismo, Universidade Federal de Uberlândia - UFU. mariaelizaguerra@faued.ufu.br

${ }^{2}$ Mestranda em Arquitetura e Urbanismo, Universidade Federal de Uberlândia - UFU. ana_isaandrade@hotmail.com
} 


\section{INTRODUÇÃO}

A consciência ecológica contemporânea veio se formando a partir da crítica à falsa eficácia de muitos edifícios, a partir da constatação de que as cidades atuais baseiam-se na repetição, em grande escala, dos mesmos erros presentes na relação entre os edifícios e o ambiente, especialmente a partir da década de 1960, com o uso abusivo da climatização artificial (AGUIAR, 2008).

A crescente importância ecológica fez emergir estudos voltados à arquitetura bioclimática. No fim da década de 1980 e inicio da década de 1990, surge o conceito de arquitetura verde, esse conceito evoluiu e consagrou a ideia de arquitetura sustentável. Para Corbella e Yannas (2003, p.17), a arquitetura sustentável:

É a arquitetura que quer criar prédios objetivando o aumento da qualidade de vida do ser humano no ambiente construído e no seu entorno, integrando as características de vida de clima locais, consumindo a menor quantidade de energia compatível com o conforto ambiental, para legar um mundo menos poluído para as futuras gerações [...] Porém o desenvolvimento dessa arquitetura é um dos desafios que enfrenta a presente geração de arquitetos brasileiros.

Inseridos nessa contextualização, cabe esclarecer também dois conceitos de referência: sustentabilidade e cidade sustentável. A sustentabilidade é um conceito criado para fortalecer a teoria e prática referente aos problemas da urbanização, tais como escassez de recursos e de contaminação, além da mudança climática.

Nesse sentido, a proposta de uma cidade sustentável baseia-se naquela que apresenta um desenvolvimento equilibrado, que é bem planejada, garantindo respeito à função ambiental, social e à dignidade humana (VASCONCELOS, 2011). "Seu desenvolvimento presente não pode deixar como legado a falta de planejamento, a degradação socioambiental, a dívida ecológica etc., nem seus problemas presentes podem ser exportados para o futuro" (AGUIAR, 2008, p. 285). Segundo Santos e Hardt (2012), ela também deve estar relacionada aos ambientes naturais apresentando estado de equilíbrio entre componentes da natureza, desde aqueles de ordem física- clima, ar, água, solo e subsolo- até os outros de origem biológica- fauna e flora. E também deve apresentar condições de relativo estado de 
equilíbrio ao ambiente antrópico, considerando, dentre outros, aspectos territoriaisuso do solo, infraestrutura e serviços urbanos- e socioeconômicos (KOGA, 2003).

Para Montaner (2012), o desafio atual consiste em demonstrar que a arquitetura verde, além de necessária e adequada socialmente, pode ser altamente atraente do ponto de vista estético, conceitual e cultural da cidade.

\begin{abstract}
A chave consistiria em deixar de conceber a arquitetura como criação única e singular, de edifícios autônomos e isolados, produtos definitivos e acabados, grandes máquinas do consumismo, passando a considerá-la e a praticá-la como estratégias e processos que se relacionam entre si, como sistemas de relações, soma de conhecimentos especializados no entorno, infiltrações de sistemas abertos e fechados, formas cuja matéria essencial é a energia, ambientes para os sentidos e para a percepção. Mais que uma arquitetura que siga estruturas tipológicas, é preciso uma arquitetura de bolhas habitáveis, de ambientes saudáveis e transformáveis (MONTANER, 2012, p. 158).
\end{abstract}

Diante desse contexto, é imprescindível entender as potencialidades da arquitetura verde como contribuição para a cidade sustentável. A mesma se baseia em uma ecologia do construído, busca enfrentar a recuperação de territórios degradados e garante o reequilíbrio ecológico da relação entre os seres humanos e o seu entorno artificial, a qual, geralmente acaba sendo esquecida em detrimento da criação de objetos isolados para a prática do consumo.

Assim, é relevante uma arquitetura que construa sem destruir, que ative o existente, que recicle o construído, que restitua as coberturas vegetais ao território urbanizado, que entenda os recursos como patrimônio e que interprete o meio existente como um complexo sistema de relações entre os seres humanos e o entorno construído. Segundo Gregotti (1994), uma arquitetura de morfologias escalonadas, de espaços coletivos e pátios, de estruturas abertas e leves que criem ambientes ventilados e climatizados, em um contexto de um urbanismo que integre as redes sociais existentes, que reequilibre transformações, modelem fluxos, estabeleça continentes flexíveis, que proponha complexos multifuncionais, que encadeie sistemas de parques.

Sabe-se que os critérios para projetar, de acordo com os princípios ecológicos, são complexos e variam em cada contexto, segundo a disponibilidade de tipologias, de recursos tecnológicos e de materiais adequados à integração ao meio, 
podendo-se valer de praças cobertas, pátios, estufas, galerias, terraços, paredes térmicas, etc. Não é possível definir normas gerais para que uma arquitetura seja ecológica, já que serão diferentes a cada contexto, mas é possível recorrer a padrões considerados sustentáveis para as cidades.

Desse modo, a presente pesquisa tem como objetivo abordar sobre as tipologias ou padrões que contribuem para uma boa relação com o meio e que visem à sustentabilidade, apontando exemplos nacionais e internacionais de cidades que vêm desenvolvendo essas práticas. Espera-se que a mesma demonstre aos designers, engenheiros, arquitetos, políticos, pesquisadores da área e a sociedade civil em geral, que a inserção da arquitetura verde no ambiente urbano contribui para a redução da emissão de gases poluentes, o consumo de energia elétrica, de bens naturais comuns, de resíduos, e outros. Espera-se também que a pesquisa motive os arquitetos, engenheiros e responsáveis a divulgarem / projetarem e implementarem cada vez mais as práticas sustentáveis, tendo como referência as exemplificações que lidam com os problemas urbanos de forma promissora.

\section{METODOLOGIA}

Para o desenvolvimento da presente pesquisa foi realizado um levantamento bibliográfico das temáticas correlatadas à sustentabilidade para o aprofundamento do conhecimento sobre a categoria de análise do espaço urbano. Foram feitas leituras em livros, artigos, dissertações, teses disponíveis eletronicamente sobre a arquitetura verde, qualidade bioclimática, cidade sustentável, tipologias sustentáveis. Foram utilizadas imagens de endereços eletrônicos, ilustrativas e que abordam o tema em discussão, com a finalidade de ampliar a interpretação e a construção de ideias.

Primeiramente, foi abordado sobre os problemas urbanos e a inserção da arquitetura verde nesse contexto. Depois, a pesquisa seguiu para a segunda etapa, destacando os recursos tipológicos que favorecem a relação com o meio, foram detalhados as formas tradicionais da arquitetura verde em relação à qualidade bioclimática, sendo eles: o pátio, estrutura em palafitas, as coberturas verdes ou 
escalonadas e a forma semienterrada. Posteriormente, abordou-se sobre o tema tecnologia para a sustentabilidade destacando as técnicas e os materiais que podem ser empregados para contribuir para que a arquitetura seja sustentável, as estruturas leves e os materiais saudáveis. Por fim, enfatizaram-se as iniciativas de cidades que estão resolvendo seus problemas de forma criativa através de princípios sustentáveis.

Ressalta-se que a presente pesquisa se caracteriza como sendo de revisão. Os trabalhos de revisão são estudos que analisam a produção bibliográfica em determinada área temática, neste caso em específico sobre a arquitetura verde e a tecnologia para sustentabilidade. Esse tipo de pesquisa é importante, pois fornece uma visão geral ou um relatório do estado da arte sobre um tópico específico, neste caso, sobre a importância da arquitetura sustentável para o ambiente urbano, evidenciando novas ideias, métodos, subtemas que têm recebido maior ou menor ênfase na literatura selecionada. A consulta a este tipo de trabalho propicia ao pesquisador tomar conhecimento, em uma única fonte, do que ocorreu ou está ocorrendo periodicamente no campo estudado, podendo substituir a consulta a uma série de outros trabalhos. As revisões podem também contribuir com sugestões de ideia para o desenvolvimento de novos projetos de pesquisa (NORONHA, 2000).

Para Moreira (2004), esse tipo de estudo é uma ferramenta importante para a investigação, pois propicia ao pesquisador tomar conhecimento, do que ocorreu ou está ocorrendo periodicamente no campo estudado. Trata-se, portanto, de um tipo de texto que reúne e discute informações produzidas na área de estudo. Ou seja, é necessário tomar como base os avanços já realizados e, por que não, as limitações dos estudos anteriormente dedicados ao tema.

Fornece informações para contextualizar o problema que se maneja, aponta e discute possíveis soluções para problemas similares e oferece alternativas de metodologias que têm sido utilizadas para a solução do problema (MOREIRA, 2004).

\section{RECURSOS TIPOLÓGICOS QUE FAVORECEM A RELAÇÃO COM O MEIO}

\subsection{Qualidades Bioclimáticas}


será o aproveitamento da luz solar, podendo evitar o uso da iluminação artificial. O uso de prateleiras reflexivas também permite a passagem de luz solar.

\subsection{Estruturas Leves para a cooperação e Materiais Saudáveis}

Para Montaner (2012), a obra do arquiteto Shigeru Ban é uma demonstração de que a arquitetura para a cooperação deve ser leve e desmontável. Sem menosprezar os valores da construção tradicional, especialmente pela capacidade de inércia térmica das vedações, o futuro de uma parte da arquitetura ambiental encontra-se nas estruturas leves e industriais, com as quais é muito mais viável construir por meio de camadas não aderentes, com elementos substituíveis, gerando-se o mínimo possível de resíduos tanto na execução da obra quanto em sua desmontagem e reciclagem.

De acordo com Edwards (2008), deve-se evitar a exclusividade funcional, pois os edifícios definidos de um modo demasiado específico são inflexíveis. Devese valorizar a simplicidade funcional do projeto, os edifícios muitos complexos resultam em inconvenientes em longo prazo. A facilidade das instalações dos sistemas de construção permite melhorá-los periodicamente e promove a legibilidade e o respeito pelo edifício.

Em relação aos materiais de construção, há aqueles naturais que são considerados saudáveis. Para EDWARDS (2008), o problema é que o baixo rendimento técnico dos materiais orgânicos faz comque os arquitetos elejam produtos artificiais. Para esse mesmo autor, os principais materiais orgânicos são:

- Produtos da Terra: blocos de terra, tijolos cozidos ao sol, argamassa;

- Pedra: A pedra possui durabilidade, é saudável e atrativa;

- Madeira de reflorestamento: É um produto sustentável e auto-renovável;

- Pinturas à base de água: Existe uma grande quantidade de pinturas que não utilizam óleo como base. Dado que sua base é aquosa, não apresentam nenhum risco para a saúde dos operários nem dos ocupantes do edifício. 
professores e técnicos da Universidade Federal de Uberlândia. O primeiro para o quarto campus da UFU na cidade de Uberlândia/MG: Campus Glória, um localizado na cidade de Ituiutaba/ Triângulo Mineiro e outro em Monte Carmelo/ Alto Paranaíba.

Conceitualmente todos centram nos princípios de sustentabilidade, de urbanidade e dinâmica urbana, priorizando o pedestre. Propõem projetos urbanísticos que entendem que tudo se inter-relaciona nos ecossistemas naturais e urbanos, na busca de reduzir desperdícios e promover a preservação de recursos naturais.

Neste sentido, a busca pela sustentabilidade ambiental, a partir do conceito de energias renováveis e sua aplicação em um contexto mais amplo abrange o uso de energia solar; reaproveitamento de águas; resíduos diversos tratados; coleta de águas pluviais e reuso; permeabilidade do solo; permeabilidade visual; eficiência energética e revegetação.

Atualmente, buscam-se medidas eficientes nas diversas atividades que são produzidas pelo homem, inclusive na arquitetura, as novas tipologias surgem, no intuito de auxiliar arquitetos e projetistas a empregarem critérios de sustentabilidade em seus projetos. É importante destacar que a harmonia de um conjunto construído reforça-se pelo enfoque coerente do desenho em várias escalas e em todas as fases de planejamento, pensando a flexibilidade aliada ao conceito de mutabilidade, algo mais significativo do que simplesmente flexível para proporcionar a a condição de urbanidade, entendida como condição de vitalidade urbana que resulta da complexidade das relações humanas.

A partir das tipologias e dos exemplos urbanos nacionais e internacionais exemplificados nesta pesquisa, recomenda-se uma consulta detalhada de cada projeto apresentado, para maiores conhecimentos e esclarecimentos sobre os critérios de sustentabilidade empregados.

\section{CONSIDERAÇÕES FINAIS}

Atualmente, cresce as preocupações relacionadas aos problemas ambientais. Os edifícios fazem parte das cidades e seu desenho, inspirado na 
análise do ciclo de vida, também podem contribuir para a sustentabilidade. Os mesmos podem gerar sua própria energia, captar e reciclar sua própria água, utilizar materiais produzidos a partir de resíduos ou manter o equilíbrio entre CO2 utilizando em sua construção a plantação de árvores.

Sabe-se que arquitetura por si só, não consegue resolver todos os problemas ambientais da cidade, mas contribui significamente para a criação de tipologias ou padrões sustentáveis. Podem selecionar também materiais de construção que sejam ecológicos ou saudáveis, com a finalidade de manter a biodiversidade local ou regional através dos produtos ou materiais utilizados. Além de favorecerem o contato com a natureza, e isto é feito plantando espécies vegetais no interior e no exterior dos edifícios, dando visibilidade a essa paisagem natural.

Já existem, conforme afirma Rogers (2008), programas tecnológicos computacionais disponíveis que geram modelos capazes de prever o movimento do ar, os níveis de iluminação e o ganho de calor em um edifício, enquanto o projeto ainda está em fase de elaboração. É possível então, pensar as cidades como sustentáveis, e elas devem ser justas, onde a alimentação, abrigo, educação, saúde sejam distribuídos de forma justa. Devem ser bonitas, onde arte, arquitetura e paisagem estejam interligadas. Ecológica, a qual minimiza seu impacto no meio ambiente, reciclando materiais, reduzindo o lixo, conservando os recursos não renováveis e insistindo no consumo dos renováveis.

Devem ser compactas, maximizando a proximidade, pois os núcleos compactos reduzem a necessidade de deslocamento de automóveis, e pode-se também criar núcleos compactos unidos por transportes de massa em reposta às demandas locais. Devem ser fácil, onde o âmbito público planeje uma adequada mobilidade para seus cidadãos.

Com o auxílio das exemplificações abordadas nesta pesquisa, pode-se definir a cidade sustentável como aquela que garante o equilibrio, que é bem planejada por meio de uma ampla compreensão das relações sociais, políticas, econômicas e ambientais. A arquitetura verde, o urbanismo e o planejamento urbano podem nos proporcionar ferramentas cruciais para garantir nosso futuro, através da criação de cidades com ambientes sustentáveis. Porém, a cidade sustentável é 


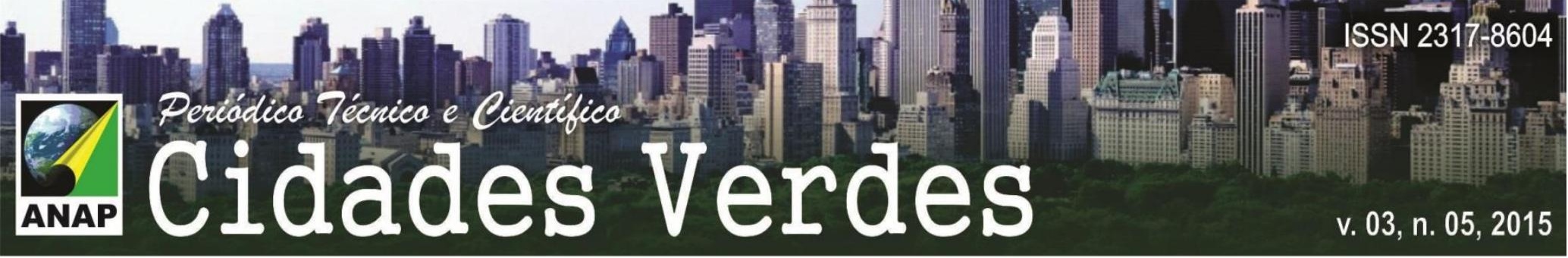

SANTOS, Ricardo C. dos, \& HARDT, Letícia P. A. Qualidade Ambiental e de Vida nas Cidades. In: Planejamento e Urbanismo na Atualidade Brasileira: objeto teoria prática. Rio de Janeiro, Ed. Livre Expressão, 2013.

VASCONCELOS, A. C. F. Índice de desenvolvimento sustentável municipal participativo: uma aplicação no município de Cabaceiras- PB. 159 f. Dissertação (Mestrado em Engenharia de Produção)- Universidade Federal da Paraíba, João Pessoa, 2011. 